firefighters. The aim was to evaluate the cancer incidence in Swedish firefighters.

Methods This cohort study is based on the Swedish part of the Nordic Occupational Cancer (NOCCA) project, including 6 million people who participated in one or more population censuses in 1960, 1970, 1980 and 1990. Cancer diagnoses 1961-2009 were obtained from the Swedish Cancer Registry. We identified 8136 male firefighters. Female firefighters were excluded because there were too few. SIRs were calculated with the cancer incidence rates for the entire national population used as reference rates.

Result There was no excess risk for all cancer sites combined ( $\mathrm{SIR}=1.01,95 \% \mathrm{CI}: 0.96$ to 1.06$)$. A statistically significant excess was found only for non-melanoma skin cancer ( $\mathrm{SIR}=1.48,95 \% \mathrm{CI}: 1.20$ to 1.80 ), although the risk did not increase with duration of employment. There was a small, but statistically significant excess of prostate cancer among firefighters who had worked 30 years or more.

Discussion The risk of prostate cancer was increased among longterm exposed firefighters, and a possible excess of non-melanoma skin cancer was found. An increased risk of prostate cancer has been reported in some earlier studies of firefighters, but excesses of others cancers earlier reported in association with firefighting were not confirmed. Our results do not support an overall excess risk of cancer among Swedish firefighters.

\section{MYOCARDIAL INFARCTION AND RETURN TO WORK}

${ }^{1} \mathrm{E}$ Gadzicka*, 'J Siedlecka, ${ }^{1} \mathrm{~T}$ Makowiec- Dąbrowska, ${ }^{1} \mathrm{P}$ Viebig, ${ }^{1} \mathrm{~A}$ Szyjkowska, ${ }^{2} \mathrm{~K}$ Wranicz, ${ }^{3} \mathrm{E}$ Trzos, ${ }^{3} \mathrm{M}$ Kurpesa, ${ }^{4} \mathrm{~W}$ Szymczak, ${ }^{1} \mathrm{~A}$ Bortkiewicz. ${ }^{1}$ Nofer Institute of Occupational Medicine, Department of Work Physiology and Ergonomics, Lodz, Poland; ${ }^{2}$ Medical University of Lodz, Department of Electrocardiology Poland; ${ }^{3}$ Medical University of Lodz, Department of Cardiology, Poland; ${ }^{4}$ University of Lodz, Department of Psychological Research Methodology and Statistics, Poland

\subsection{6/oemed-2018-ICOHabstracts. 1078}

Introduction After myocardial infarction (MI) only 50\% to $60 \%$ of people still work and the time to stay out of work is in Poland often 9 months. The aim of the project was to elicit factors that have an impact on the return to work after the first myocardial infarction.

Methods A questionnaire survey was performed among all patients occupationally active till the time of the MI. The questionnaire covered recent data on work, working environment, health status, lifestyle. 306 people received the questionnaire. The analysis included 150 surveys.

Results As much as $76.7 \%$ (115) people returned to work. The average age of workers prior to infarction was 52.6 \pm 7.1 years, and was significantly lower than that of people who did not return $(55.3 \pm 6.8)$. The subjects returned to work after an average of 6.5 months (range $0.5-48$ ). The group of people who returned/did not return to work did not differ in respect to education, place of residence, classical risk factors, type of MI, ejection fraction and undertaken rehabilitation. Subjects who returned to work significantly more likely used to undertake physical activity. People who did not return to work significantly more often rated their health as 'worse than before the MI' $(\mathrm{p}=0.026)$ complained the chest pain $(71.4 \%$ vs $38.6 \%, p=0.026)$, suffered from neurosis $(25,7 \%$ vs $10.4 \%, \mathrm{p}=0.047)$ and were anxious about re-infarction (71.4\% vs $49.6 \%, p=0.023)$. As many as $20.9 \%$ of subjects claimed that the work was too heavy, while for $49.6 \%$ the job was too stressful.
Discussion The results indicate that age, subjective health status and the presence of pain in the chest, neurosis and anxiety play an important role in the return to work after MI. For people who restarted working, work heaviness and stress occurring at work were the major problems.

\section{DIETARY HABITS IN OCCUPATIONALLY ACTIVE MEN WITH FIRST MYOCARDIAL INFARCTION}

${ }^{1}$ A Bortkiewicz*, ${ }^{1} E$ Gadzicka, ${ }^{1} \mathrm{~J}$ Siedlecka, ${ }^{1} \mathrm{~A}$ Szyjkowska, ${ }^{1} \mathrm{P}$ Viebig, ${ }^{2} \mathrm{JK}$ Wranicz, ${ }^{3} \mathrm{M}$ Kurpesa, ${ }^{3} \mathrm{E}$ Trzos, ${ }^{1} \mathrm{~T}$ Makowiec-Dąbrowska. ${ }^{1}$ Department of Work Physiology and Ergonomics Nofer Institute of Occupational Medicine Lodz, Poland; ${ }^{2}$ Department of Electrocardiology, Medical University of Lodz, Poland; ${ }^{3}$ Department of Cardiology Medical University of Lodz, Poland

\subsection{6/oemed-2018-ICOHabstracts. 1079}

Introduction Only a few studies have been undertaken to analyse the dietary habits of people with cardiovascular diseases. The aim of this study was to evaluate the dietary behaviours of working people after the first acute cardiovascular incident. Methods In the study Functional Activity Questionnaire (FAQ) was used. The study was performed in two groups: the first group were all men hospitalised during one year in two clinics of cardiology, professionally active until the first myocardial infarction (MI). It comprised 243 men, aged 26-70 years. The reference group consisted of 403 men, blue- and white-collar workers aged 35-65 years. Frequency of consumption of each product among patients with acute myocardial infarction and in the reference group was calculated using basic methods of descriptive statistics. Multivariate logistic regression model was used to determine the risk factors for myocardial infarction. All statistical analyses were performed using the STATISTICA version 8 MR 3 c software.

Results Body mass index of MI patients was significantly higher $(p=0.006)$. The frequency of consumption of particular products in MI group and in the reference group differed significantly for 11 of 21 products. Patients with MI significantly less frequently reported daily consumption of fruits, raw vegetables, cheese, vegetable fats and fish. In this group consumption of salty $(p=0.0226)$ or fatty $(p<0.0001)$ foods were significantly higher.

Discussion It has been shown that after adjusting for age, education and type of work, the daily consumption of fish, salads and cooked vegetables, fruits and vegetable oils significantly reduced the risk of myocardial infarction. Increased MI risk was associated with obesity and preference for fatty foods. We found, that the diet significantly modified risk of MI in examined workers. This indicates that an important part of prevention activities among working people should be an education about proper dietary habits.

\section{A HEALTH-BASED RISK ASSESSMENT FRAMEWORK IN THE WORKPLACE TO INTEGRATE THE MANAGEMENT OF HEALTH AND SAFETY RISKS: A REVIEW}

Jeff Yi-Fu Hwang*, Sin Eng Chia, Judy Sng. Saw Swee Hock School of Public Health, National University of Singapore, Singapore

\subsection{6/oemed-2018-ICOHabstracts. 1080}

Introduction Despite significant global improvement in occupational health and safety over the past few decades, workplace deaths and injuries are still occurring. At the same time, many 